\section{ORGANISATION AND WORK OF THE CAVENDISH LABORATORY*}

\author{
By SIR LAWRENCE BRAGG, O.B.E., F.R.S.
}

$\mathrm{T}$ HE Cavendish Laboratory is faced with problems which are common to most scientific laboratories in this post-war period, and arise from the great expansion in the numbers of undergraduate and graduate students. Part of this increase is a temporary phenomenon. Men are being released from the Forces who have missed the whole or part of their undergraduate time at the university, and are returning to swell the classes. The increase in the first- and second-year students at Cambridge is perhaps not as great as it is in other universities, because the undergraduate population is limited by college accommodation; in physics these classes at present are some 50 per cent greater than they were before the War. The numbers in the final honours class, however, have almost trebled, because men returning from war-work for the most part join this class, which now has about a hundred and twenty students. It will probably remain considerably higher than its pre-war level, because the recommendations of the Barlow Report reflect the need of the nation for more scientists, and demand is creating a supply. The greatest increase of all is in the number of research students, and here the Laboratory is crowded to capacity, if not overcrowded. Although all available places are used, the number of those who apply for admission as research students is three or four times as great as the number which can be accepted each year. More than a hundred and sixty researchers are now working in the Laboratory, of whom 110 are research students working for their Ph.D. degrees -between one-fifth and one-sixth of the total number registered for research degrees in Cambridge.

This large increase implies a major change in the organisation of the Laboratory. The old days when the head of the department could be in close contact with all his research students are a matter of the past. There would appear to be a limit in organisations of all kinds to the number of men whom any one head can direct by close personal contact, this number being about six. It applies in the direction of research as well, and devolving of responsibility is essential when numbers rise above this limit. Even before the War, numbers of researchers in the larger laboratories were approaching the $6^{2}$ level, and now they are in the $6^{3}$ region. In other words, the organisation of the research work involves splitting up the men into large groups under leaders, and these again into smaller groups, so that the head of the department is two removes from the researcher himself. Except in a few special cases of work in which he is particularly interested, he cannot afford to spend that twoor three-hour period every fortnight or so talking over his work with the individual, which is essential for real direction.

The major groups in the Cavendish Laboratory are nuclear, radio and low-temperature physics, crystallography, metal physics and mathematical physics, with some minor groupings. It may be interesting to give some account of the extent to which these groups are independent, and of the common ground on which they meet. The great foe of research is administrative

* From a course of three lectures at the Royal Institution on March 4,11 and 18 . responsibility. A nice adjustment has to be made between giving the heads of groups as much freedom as possible to make their plans for using their facilities to the best advantage, and at the same time relieving them of the more tiresome and mechanical details of administration which can be properly centralized. In our organisation each group has its own allocation of the budget for the year, and its own order-book, so that apparatus and supplies can be bought within that budget; each has its own staff of assistants and its workshop; it has its own secretary for clerical work; further, each group runs its own colloquium, where scientific papers from other laboratories are discussed and the researchers give reports of their progress. The days are past when most researches in a department were on closely related lines and a joint colloquium was possible. A colloquium in one group or another is now an almost daily event, and no individual can spare the time to go to them all. Common touch is kept up by the fortnightly meetings of the Cavendish Physical Society, where the heads of the groups give an account of the work going on in their sections, and distinguished visitors speak, and by more informal meetings of the leading researchers, such as the little club which was founded by Kapitza when he was head of the Mond Laboratory.

The administrative burden of the teaching staff has been much lightened by the appointment by the University of a secretary to the Laboratory. This officer has in his charge finance, appointments of assistant staff and rates of pay, the formal work concerned with admissions, structural alterations and upkeep of the buildings, preparation of agenda for meetings, and other matters of this kind.

A main workshop serves all sections of the Laboratory, where work requiring special tools and skills is carried out; glass-blowing is also centralized. There is also a separate central workshop where research students can use the machine tools, where the young assistants are trained, and where repairs to class-apparatus are carried out. In addition, two special centres deserve mention. It has been found convenient to have a 'special techniques' workshop where the most highly skilled and delicate work of especial kinds is carried out, and to place this workshop in charge of a member of the staff. It is largely concerned with the construction and sealing of Geiger counters, and the purification of the gases with which they are filled. Special thermionic devices are made there, and evacuated, baked and sealed. It manufactures delicate metal parts by a photographic technique, such as supports for thin-walled windows, makes special metal-to-glass or metal-to-silica joints, and has apparatus for preparing thin metal films by evaporation. The other centre, also in charge of a member of the staff, constructs and maintains electronic equipment of all kinds, such as decimal scalars and multiple coincidence circuits, or pulse and D.c. amplifiers for nuclear work. The capital value of the electronic equipment of this kind approaches five figures, and it is a saving of time and money to place it in charge of an expert.

The largest group in the Laboratory is the nuclear physics group, under Prof. O. R. Frisch and Mr. E. S. Shire, with some forty researchers. The Cambridge equipment includes the one-million and two-million volt sets in the high-tension laboratory, and a cyclotron with $37-$ in. pole-pieces. A fivemillion volt Van de Graaff generator is being built for the Laboratory by the English Electric Company, and it is hoped to get it running by the end of 1948 . 
The maintenance of these large and complex units introduces problems of a new scale in a physics laboratory. It creates the need for a new type of staff member, the 'technical officer'. He must be a trained physicist, in general a university graduate, but a man who has the engineer's outlook and who is interested in the construction and functioning of the apparatus rather than in the research which is done with it.

The radio group represents the continuation in the Laboratory of the work which Sir Edward Appleton started when he occupied the Jacksonian chair at Cambridge; it is now under the direction of Mr. J. A. Ratcliffe. It has field stations as well as its section of the main Laboratory. The work on propagation is mainly concerned with the longer wave-lengths which are reflected below the E-layer. Another section is making measurements of the waves in the metre wave-length region coming from the sun, recording their intensity and propagation and estimating the size of the source from which they come by a method analogous to Michelson's method of measuring the angular diameter of a star.

The Mond Laboratory is now under the direction of Dr. D. Shoenberg, its former head, Dr. J. F. Allen, having been recently appointed to St. Andrews. A main interest is the properties of superconductors, in particular the penetration of magnetic fields into superconductors. It has equipment for the magnetic method of cooling. Liquid helium is at present made by Kapitza's expansion machine; but a new machine of greater capacity and more orthodox type is under construction.

In crystallography, under Dr. W. H. Taylor, the arrangement of atoms in minerals, alloys, organic compounds and proteins is being studied. The section studying proteins under Dr. M. F. Perutz and J. C. Kendrew has this year been accorded the backing of the Medical Research Council. The elucidation of the structure of such enormous and complex molecules is the most ambitious problem as yet tackled by $\mathrm{X}$-ray analysis, and success would cast a flood of light on the structure of living matter.

The metal physics section, under Dr. E. Orowan, is concerned with problems of slip and plasticity, fracture, crystal growth, and metallic phenomena in general investigated by physical methods.

The Laboratory houses an electron microscope service which is used by all departments of the University. It provides hospitality for several researchers from other departments. Particularly welcome guests are the mathematical physicists, including the Plummer professor, D. R. Hartree, who have rooms in the Laboratory.

It may be of interest to assess in round figures the cost of research in the Cavendish Laboratory. The figures must be approximate, since many of the services are common to teaching and research. As an example, in the following estimate the time of the University staff is regarded as divided equally between teaching and research, and its cost apportioned accordingly. Making similar adjustments for administration, assistant staff, stores and apparatus (almost entirely research) and so forth, the total expenditure on research in the Laboratory (including the Mond) was just short of $£ 60,000$ in $1946-47$, of which $£ 10,000$ came from outside sources. To this must be added a sum to represent the rental of the buildings, which does not appear in the estimates. In estimating the cost per research student, the abnormal position of nuclear research must be taken into account. Not only are the running expenses above the average, but also units such as the cyclotron represent a large outlay of capital, and special grants are made by the Department of Scientific and Industrial Research to meet needs which the University cannot finance from its own resources. Such requirements vary very greatly from year to year, and I have therefore only included a sum for nuclear research which corresponds to the expenditure per researcher in other branches of physics, and which roughly represents the contribution which the University itself makes towards the cost of the nuclear research. On this basis, the cost per research student is $£ 400$ a year. If to this is added $£ 350$ to represent the average maintenance grant of junior and senior workers, the total cost to the State of maintaining a research worker in the Cavendish Laboratory is $£ 750$ a year.

\section{MAN'S ORGANS OF SPEECH}

7 HE Huxley Memorial Lecture for 1947, under the auspices of the Royal Anthropological Institute, was delivered by Dr. W. L. H. Duckworth, reader emeritus in human anatomy in the University of Cambridge. The subject was "Some Complexities of Human Structure"*. The approach was frankly anatomical and was a meticulous and masterful analysis of the facts, anatomical and racial, relating to the organs of speech in man. Duckworth wasted no time on the classical definitions of anthropology; he ignored the subdivisions of the subject and refused to be drawn into the finer distinctions of zoological anthropology, physical anthropology, social and cultural anthropology and ethnology. He kept clear of the pathological and avoided the theories of aphasia from Broca and Bastian to Henry Head. Here was the approach to the anatomical aspect as emphasized by Galen in his "Methodus Medendi" : "The magnitude of a disease is in proportion to its deviation from the healthy state; and the extent of the deviation can be ascertained by him only who is perfectly acquainted with the healthy state". Hence the justification for the intensive study of normal structure and function in man as distinct from booksellers' notes about positive health and social medicine.

Duckworth dealt in turn with our present knowledge of the anatomy of the organs of speech, from lips, tongue, jaw, palate to the component parts of the larynx and finally the brain. To listen to so distinguished an anatomist, who is also the doyen of physical anthropologists, survey the field, much of his own ploughing and harrowing, was an intellectual feast. Rarely has a lecturer given facts and their history, as T. H. Huxley demanded, and yet exposed the gaps in our knowledge in both anatomy and physical anthropology. His survey of the work to be done provided bone and grist for many young workers. Here surely was God's plenty for the young anatomist in the laboratory and the young anthropologist in the field. The survey from Cuvier's postulate that articulate speech was the distinctive character of man to the vast modern demands of phonetics, linguistics and psychology was a criticism and yet a stimulus to the biological study of the organs of speech, emphasis being laid on the need for perfect acquaintance with the healthy normal anatomical structure.

- Some Complexities of Human Structure. By Dr. W. L. H.
Puckworth. (Huxley Memorial Lecture for 1947.) Duckworth. (Huxley Memorial Lecture for 1947.) Pp. 12. (London:
Royal Anthropological Institute, 1947.) 3s, 6d. 